\section{BRIEF CONSIDERATION OF MR. GAMGEE'S EXPERIMENTAL INQUIRY INTO THE EFFECTS OF INJECTING PUS INTO THE VEINS OF ANIMALS.}

By HENRY LEE, Esq., F.R.C.S., Surgeon to the Lock Hospital, Assistant-Surgeon to King's College Hospital, etc.

In the Association Journal for December 9th, Mr. GAMGEE has entered into a critical inquiry of the most recent opinions concerning the local effects of injecting pus into reins; and has entered at length into a consideration of my experiments upon the subject, which, he has done me the honour to say, "were, ever since their announcement, regarded as marking an era in the progress of knowledge of purulent infection."

The limits necessarily assigned to a communication to a medical journal forbid even a passing consideration of the whole subject; but Mr. Gamgee's experiments and observations afford some particular points well worthy of attention.

With regard to the principles themselves, they have been fairly stated to the profession, and have been reprinted and adopted in some of the most widely circulated surgical works in the English language. They must stand or fall by the test of pubiic experience; but I cannot for a moment allow (as appears to be inferred by Mr. Gamgee) that the conclusions arrived at depend upon the accuracy of any one set of experiments.

Already have the descriptions of subacute and acute phlebitis given way to the descriptions of the local effects of inflammation of veins, and that general contamination of the blood to which the name pyokemia has been given: affections essentially distinct in their nature, but which may nevertheless frequently co-exist in the same case. As an instance of the truth of these remarks, I may refer to the differences observable between the chapter on Injuries and Diseases of the Veins, in the fifth edition of Dr. Druitt's excellent $\mathbf{M F}$ nual of S'urgery, published in 1851, and that in the sixth edition, which has just appeared.

With these observations, then, I must dismiss the general subject, and confine myself to the particular points mentioned in Mr. Gawgee's interesting inquiry.

The first sentence selected by Mr. Gamgee for especial criticism, and twice published for that purpose, is as follows:- "The simple experiment of mixiug some pus with healthy recently drawn blood will at once show that such a hembing in the living body. It will be found that the blood coagulates round the globules of pus, and forms a solid mass, which will adhere to the first surface with which it comes in contact."

It must be evident that, in this sentence, the relative "which" refers to its antecedent "solid mass", and not to the globules of pus; and it would be therefore most unfair to draw from it the additional conclusion, that no time was occupied in forming the solid mass, or that pus could, under no circumstances, be made to pass along the bloodvessels. If such an inference could have been drawn from a single sentence, it might surely have been corrected by other statements in the same work (On Phlebitis, etc.). Thus, at page 43 , I write, that the experiments show that pus has a tendency to coagulate the blood; and that, from this cause, "its progress is arrested in some part of the circulating system"; and at page 24 I state that, "where purulent or other fluids have been directly injected into the blood, the examination of the blood or of the ressels will by no means indicate the presence of foreign matter, nor will inflammation of the vein through which the fluid has passed be by any means invariably produced." Finally, I have myself detailed four cases in the work referred to, in which pus was injected into the veins without producing any characteristic local morbid appearances. It appears, therefore, strange to me, that Mr. Gamgee should have inferred from my writings that I was of opinion that pus could never be made to pass into the circulation, and that he should have endeavoured to prove, in supposed opposi- tion to my experiments, that "the circulation of pus with the blood is perfectly possible".

"To argue, as Mr. Lee does," continues Mr. Gamgoe, "from the fact that, out of the body, blood coagulates round pus, therefore such a combination cannot circulate in the living body, is about as warrantable as it would be to predicate from the observation, that pure blood coagulates in a basin, it therefore cannot remain fluid in the ventricles of the heart."

With this criticism, though somewhat complicated, and manifestly inappropriate, as applied to a peculiarity in the mode of coagulation, I have, on the whole, not much fault to find, since Mr. Gamgee has himself furnished the evidence that vitiated blood, to which alone my experiments referred, will not always remain fluid in the ventricles of the living heart.

"A mixture of two drachms and a scruple of good pus, diluted with an equal quantity of tepid water, was injected", says Mr. Gamgee, "into the right jugular vein. I had no sooner done this, and transfixed the lips of the orifice with a pin, than the horse began to heave at the flanks, after which he staggered a few moments, and fell; when down, he breathed laboriously thirty-eight times in the minute, and, with scarcely a struggle, and not more than two minutes' delay, expired. . The jugular vein and the right cavities of the heart were filled with dark coloured currant jelly-like clotted blood. . . From the manner the experiment was conducted, the introduction of air into the vein was impossible. On examining the blood from the right side of the heart, I discovered on it a very large number of corpuscles, measuring, on an average, one two-thousandth of an inch in diameter, and havin $;$ nuclei not distinguishable from those of pus-cells. So numerous were they, that it was inpossible to count them."

As the horse has only one jugular vein on each side, the blood returns to the heart through it, when unobstructed, with something like the same velocity that it passes from the heart through the carotid artery: a period of four or five seconds is the utmost time that the blood would, in the ordinary course of the circulation, take to pass through the heart from the jugular vein; yet, in Mr. Gamgce's experiment, the pus is found mixed with the clotted blood in the heart, after an interval of two minutes, without reckoning the time consumed in completing the experiments, or the interval during which the circulation may have gone on after apparent death. By what power, then, I ask, were these pus-globules detained in the heart? and what was the cause of the sudden death which occurred in this case?

This experiment of Mr. Gamgee's is the more interesting, as it coincides exactly with an experiment recorded in a very able and interesting paper by Dr. Mackenzic, in the last volume of the Medico-Chirurgical Transactions. At page 200 , Dr. Mackenzie states: "The femoral vein of a dog was exposed on the $15 \mathrm{th}$ of June, 1852, and half an ounce of pus, slightly diluted with water, was slowly injected into it towards the heart. In rather more than a minute, the dog seemed distressed; the abdominal and respiratory muscles became convulsed; and respiration ceased within two or three minutes. On making a post mortem examination shortly afterwards, the vena cava and the abdominal and thoracic veins were found generally turgid with blood. On opening the right iliac vein, a stream of dark coloured tluid blood poured out; and, on continuing the division of the veins upwards, the blood was still found to be fluid, with the exception of two or three small coagula, which were found about the middle of the cava. The right auricle contained a thin black coagulum, and small fibrinous coagula were scattered over and between the columnæ carneæ of the right ventricle, which contained a minute ycllowish looking matter, closely resembling the pus which had been injected."

A third case, in which the injection of a putrid fluid produced analogous symptoms, is detailed at length in the Medical Times of the 3rd instant.

What is it, I again ask, that produces the sudden and alarming symptoms in such cases? There is no animal 
poison known which is so sudden in its operation; and that pus, simply as such, produces no such symptoms, we have abundant proof from those cases in which it has passed without obstruction in the course of the circulation.

In a Report of a Committee of the Edinburgh Physiological Society of the 9th of January, 1853, upon some experiments undertaken at the instigation of Professor Bennett, it is stated, that fresh and healthy pus was slowly injected towards the heart into the jugular vein of a donkey. A slight obstruction was at first perceived, and the vein above the ligature could be seen to be somewhat swollen. This swelling, on being felt, was very soft, and, on pressing the vein from below upward, the mixed blood and pus was readily pushed before the finger. When all obstruction to the passage of pus from the syringe was removed, the syringe was again filled, and another ounce of pus was injected, without occasioning any further local effects. The animal was then allowed to get up, and exhibited no change in its normal condition whatever. The same ass was the subject of a second experiment, a fortnight later, having been perfectly well in the interval. Six inches of the jugular vein were now exposed, and an ounce of perfectly healthy pus was then slowly injected downwards towards the heart. Another syringe full of pus was then injected. The animal presented no unusual symptom whatever during the next four days.

To what, then, are to be attributed the sudden and fatal effects observed in Mr. Gamgee's and in Dr. Mackenzie's cases? I answer, to the coagulation of the blood in the heart. It is to this that are to be ascribed the sudden and fatal results in the cases which these gentlemen have recorded; and to the absence of any such result, that the corresponding absence of symptoms must be assigned in the last mentioned experiments.

Thus, I conceive that, while it is fully demonstrated that, in certain cases, pus may pass into the circulation without producing any very manifest inconvenience, that, in others, it will produce coagulation of the blood in the lining vessels, and a train of consequent symptoms which will vary according to the locality in which such stagnation has taken place. What the circumstances are which, in one case, will determine this effect, and in another not, will form the sulject of a separate inquiry. For the present, I must content myself with having shown, as I believe, from independent evidence derived from experiments undertaken to illustrate other and different views, that the doctrine which I first published in 1849 is not devoid of foundation; and that the propositions which $I$ then endeavoured to establish,-namely, that pus and some other morbid fluids, when mixed with the blood, have a tendency to produce its coagulation, and that this tendency is often more quickly manifested in the body than out of it,-have been fully demonstrated.

15 Dover Street, Piccadilly, Dec. 13th, 1883.

\section{DESCRIPTION OF A NEW BEDSTEAD FOR DIRTY INSANE PERSONS.}

\author{
By JAMISS G. DAVEY, M.D.
}

[Read before the Anniversary Meeting of the Provincial Medical and Suryical Associution, dugust 11 th, 1853.]

Amosg the insane there are, and always must be, even in the best recrulated of asylums, and with the greatest care and attention, a considerable number whose mental existence is relucel to so low an ebb, that the calls of nature are either not heeded, or are kept in abeyance by an inordinate cerebral excitcment, or by some absorbing and abnormal impulse, which involves the volition of the party affecter in disorder and irregularity (mania). These constitute what in asylum parlance are called dirty patients; and, for their management. and accommodation, various plans have, at different times, been suggested. In the olden time, this class of patients was very summarily dealt with. $\Lambda$ little loose straw, and that not over clean, was thrown into the corner of a damp and dirty cell; and the poor lunatic was fortunate indeed to have this exchanged when it was needed. At a less distant period, the straw was put into a coarse kind of sacking. After the lapse of time, however, both the loose straw and the coarse straw mattresses were abandoned, and their place was supplied by the common stretcher. This consists only of a stout piece of canvas extended over a framework of wood, of the length and breadth of the crib, and into which it is received. This arrangement is not unattended with much danger, inasmuch as violently disposed persons commonly remove the stretcher, and use it as a weapon of offence ; or not infrequently break it into pieces, and do more or less mischief in and about the dormitory. To meet these grave objections, various ingenious plans are derised to fasten or lock the stretcher to the crib or bedstead.

Two objections are made, and very properly, to these stretchers: one is, that the canvas, if sufficiently strong, is not porous enough to allow the urine to escape ; it is, therefore, retained more or less about the person of the patient, and risk is thereby incurred of sores: the other is the time and labour demanded, not only to wash and dry the stretcher for further use, but to carry it to and from the laundry and the wards.

The first objection has been met by piercing holes in the canvas, similar to those which tailors are in the habit of making on the back parts of waistcoats, to enable us, in physiological phrase, to adapt the containing to the contained parts. The due escape of the animal fluids, however, leaves yet the second objection untouched; and to remore this very serious business, in a lunatic asylum containing any number of patients, is the especial purpose of the cane bedstead, to which I would here call attention.

By referring to the drawing, it is seen that the whole depth of the crib is divided into two parts, an under and an upper, by the cane flap or partition which intersects it in its whole length and breadth. On the one side of the interior of the crib, the cane flap or shifting bottom is held on hinges; and, on the other side, it fastens with a kind of spring lock, which is opened from the outer side or exterior by a key of a peculiar construction. The specific value of the above arrangeunent consists in the employment of cane in the stead of canvas. This material, from the great abundance of silica which it contains, mixed with regetable matter, offers a non-absorbing surface to the urine; and all the washing, therefore, which it requires may be performed hy a damp piece of flannel, which may be used daily by the ward-attendants themselves in the dormitory, as the crib stands, with scarcely any trouble. (Figs. 1 and 3.)
Fig. 1.

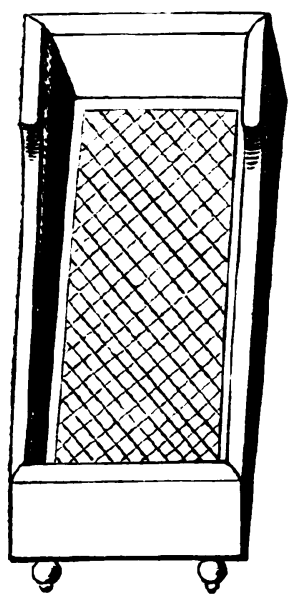

Fig 2.

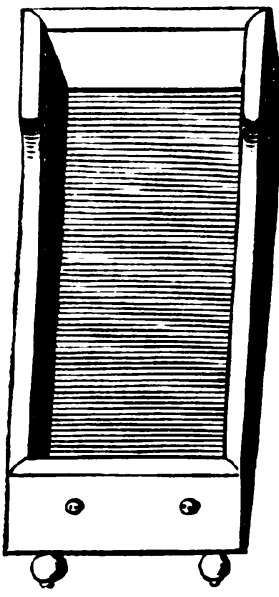

Fig. 1 represents the bedstead with the cane flap put down, and in position for use. On the rane flap the bedding is placed. N.B. The finer the canework the better.

Fig. 2 represents the bedstead with the canras expanded by the iron rods placed on either side: and which, passing from the head to the foot-board, preserre the same in sitw. 